\title{
ÉTICA PROFISSIONAL E INTERDISCIPLINARIDADE: PARTILHA DE INFORMAÇÃO E CONFIDENCIALIDADE EM SEDE DE EQUIPAS MULTIDISCIPLINARES
}

\author{
Rosa da Primavera Castro ${ }^{1}$
}

\begin{abstract}
Resumo: A informação, com todas as suas potencialidades $e$ limites, é um recurso que deve ser gerido no sentido de contribuir para o alcance dos objectivos profissionais, e é essencial que exista um plano estratégico de informação, devidamente articulado $e$ coerente com a missão e objectivos da instituição onde se desenvolve a acção profissional. A confidencialidade da informação, no âmbito das equipas multidisciplinares, e a possibilidade da sua quebra, levantam, frequentemente, questões de natureza ético-legal, manifestadas nas expressões: o que devo saber? o que devo fazer com o que sei? e o que devo partilhar do meu saber?

A preocupação de agir eticamente no processamento $e$ comunicação de dados pessoais, que geram informação, deve obedecer a um rigoroso respeito pelos direitos do homem e pelas liberdades e garantias consagradas na lei e na constituição.

A ética profissional deve ter subjacente um processo de tomada de consciência, que não derive de uma simples situação de vazio que é preciso preencher. Ela deve derivar de uma vontade e autêntica conformidade entre pensamento e comportamento profissional (Projecto Profissional).
\end{abstract}

Palavras-chave: Ética Profissional, Informação, Confidencialidade, Interdisciplinaridade, Equipas Multidisciplinares.

Abstract: Information, with all its potential and limitations, is a resource that should be managed in order to contribute to the achievement of professional goals. It is essential to have a strategic information plan adequately articulated and consistent with the mission and objectives of the institution where the professional action

1 Universidade Católica Portuguesa, Centro Regional das Beiras - Pólo de Viseu Departamento de Economia, Gestão e Ciências Sociais. E-mail: rosadaprimavera@ sapo.pt 
is developed. The confidentiality of information in the context of multidisciplinary teams and the possibility of the breach thereof, frequently raise ethical and legal issues, implied in expressions such as: What should I know?, What should I do with what I know?, and What aspects of my knowledge should I share?

The concern regarding ethical manoeuvring in the course of processing and communicating personal data that lead to information, ought to obey a strict code of conduct regarding human rights and freedoms as well as guarantees enshrined in the law and constitution.

Professional ethics should rely on a process of awareness which does not emerge from a void that needs to be filled. Instead, it should derive from a willingness and real conformity between thought and professional behaviour. (Professional Project).

Keywords: Professional Ethics, Information, Confidentiality, Interdisciplinary, Multidisciplinary Teams.

\section{INTRODUÇÃO}

Actualmente, as instituições/organizações reúnem uma vasta diversidade de profissionais com diferentes tipos de formação teórica e técnica, e com diferentes posições hierárquicas, formais e informais, que muitas vezes, para cumprirem os seus objectivos, têm necessidade de partilhar e gerir informação. Esta associação subentende, em termos práticos, o designado trabalho em equipa.

As características das instituições e da formação teórico-metodológica dos diversos profissionais que nela participam são, provavelmente, os primeiros pressupostos que se colocam nesta análise. Nesta consideração, também é importante realçar o "papel da Ciência e do Saber e as suas relações com o poder" (Sá, 2000:9), na concorrência solidária das várias disciplinas para a compreensão da realidade humana.

No entanto, construir um verdadeiro trabalho de equipa não é tarefa fácil e requer duas componentes fundamentais: interdisciplinaridade e cooperação (Golin \& Ducanis, 1981). A interdisciplinaridade implica troca, reciprocidade, complementaridade, ou seja, conhecer o outro profissional e a outra profissão na sua alteridade. A cooperação significa, em primeiro lugar, trabalhar com o utilizador dos serviços como um parceiro essencial, a ser completamente implicado em todo o processo mas, também, trabalhar com os outros membros da equipa e com outros serviços ou redes (serviços da saúde, da educação ou sociais). Implica igualmente a partilha de conceitos e de referências teóricas e uma atitude aberta e de respeito para com todos os parceiros.

Encontramos aqui uma primeira aproximação à dimensão ética no quotidiano profissional. A ética, enquanto produto do pensamento humano, não é neutra, está envolta numa intencionalidade posta em prática pelo próprio homem. Por 
isso, as diversas orientações teóricas dão origem a éticas diferentes, por vezes difíceis de contornar no campo da interdisciplinaridade profissional.

\section{Fundamentos filosóficos e conceptuais}

\subsection{Informação}

A importância da informação e do conhecimento na actividade humana é hoje universalmente reconhecida, assumindo-se que entramos numa era de criação e aprendizagem contínuas. Estes dois binómios são, nesta medida, os constituintes básicos da inovação, mas também aqueles que geram maior perplexidade no âmbito da formação e do exercício profissional.

Questões como: "o que devo saber? o que devo fazer com o que sei? e o que devo partilhar do meu saber?", entram em cena no momento de pôr em prática os desideratos profissionais.

Actualmente, os conceitos de informação e conhecimento nem sempre são bem diferenciados. A elevada importância atribuída à informação, cuja acessibilidade, as novas tecnologias elevaram a níveis surpreendentes, o profissional chega mesmo a considerar que sabe muito quando dispõe de muita informação. E, mais, se associarmos essa acessibilidade à abundância de conteúdos disponibilizados pelos meios de comunicação de massas, compreendemos a necessidade de uma atitude ponderada e reflexiva sustentada nos pressupostos de uma ética profissional.

Por estas razões, para podermos fazer uma reflexão mais compreensiva sobre a partilha de informação e os seus limites, embaçados na confidencialidade, importa recorrer aos fundamentos filosóficos e conceptuais que lhe estão subjacentes.

Na literatura sobre esta matéria, frequentemente, os conceitos de informação e conhecimento são tratados de modo semelhante. A informação é usualmente considerada como aquilo que é capaz de gerar conhecimento. O filósofo Dretske (1982, cit. in Lopes, 2005:60) identifica o conhecimento como "convicção produzida pela informação". M. Castells (2000, op. cit.) refere-se à informação como "comunicação do conhecimento". R. Junqueiro (2002, op. cit.) define conhecimento como "apreensão, compreensão e transformação da informação em acção".

A informação pode ser o resultado do processamento, manipulação e organização de dados, de tal forma que represente uma modificação (quantitativa ou qualitativa) no conhecimento daquele que a recebe (pessoa ou máquina). Genericamente, o conceito de informação está estreitamente ligado às noções de comunicação, controle, dados, instrução, conhecimento, significado, percepção e 
representação do conhecimento ${ }^{2}$. Também é conceituada como o conjunto de dados, em princípio imprevisíveis, recebidos do exterior por um ser vivo, especialmente o homem, por intermédio dos seus sentidos, ou recebidos por uma máquina electrónica; elemento ou sistema que pode ser transmitido por um sinal ou por uma combinação de sinais; aquilo que é transmitido ${ }^{3}$. Informação, por vezes, tem simplesmente o significado do que é dito ou de notícias.

Estes múltiplos significados da palavra informação podem ser agrupados em duas esferas. Uma esfera onde a informação é considerada como aquilo que é comunicado, nomeadamente, um sinal, um evento, uma história ou um facto. Outra, a informação como o resultado da actividade de procura e de recolha de dados, que concorre para o exercício de uma actividade profissional.

Assim, podemos observar que o conceito de informação inclui a noção de dados. De acordo com Alter (1999, cit. in Lopes, 2005:60), as pessoas usam o conhecimento acerca de como formatar, filtrar e sumariar dados, como parte do processo de conversão de dados em informação útil. Interpretam essa informação, tomam decisões e executam acções. O resultado dessas decisões ajuda a acumular conhecimento para usar em decisões posteriores.

Importa realçar, nesta análise, a questão inerente ao processamento da informação, uma vez que este estabelece uma estreita ligação entre informação e conhecimento. Deste modo, a aquisição de conhecimento ambíguo ou alternativo, a partir de informação incompleta, pode resultar em ambiguidade interpretativa geradora de incerteza. Já a limitação do conhecimento, a um processamento de informação, pode conduzir à interiorização de um conceito redutor de conhecimento, uma vez que a informação é um conjunto fechado e o conhecimento é essencialmente aberto e ilimitado (Fransman, Martin:1998, op. cit:61). Efectivamente, o conhecimento não resulta necessariamente do processamento de informação uma vez que a interpretação da informação pode ser ambígua, quer pela sua incompletude, quer pela existência de um conhecimento já construído no processo de socialização e formação de cada profissional.

Deste modo, a informação é uma formação interna ou interior (Ilharco, 2003:173). Este significado tem por base a origem etimológica da palavra informação. Originária do latim, o verbo in-formo, que junta as expressões in e forma para significar dar forma a uma coisa, modelar, formar, moldar, formar uma ideia sobre algo, representar, delinear, esboçar, instruir, educar e informar (Crane, 2002: op. cit). Presentemente, podemos observar que a palavra forma tem uma variedade de sentidos, destacando-se os seguintes: a figura geométrica

2 www.priberam.pt - Dicionário da Língua Portuguesa (1996), Versão 1.0, Priberam Informática e Porto Editora.

3 (idem). 
de um objecto, o seu feitio ou figura, a feição, o modo de expressão em obra plástica ou literária e a estrutura linguística ${ }^{4}$.

O filósofo romano Cícero (106-43 AC), utilizava a palavra informare com o sentido de impor uma forma sobre alguma coisa, em particular sobre a mente humana, com o objectivo de a instruir e melhorar ${ }^{5}$. A questão que mais uma vez se coloca nesta análise é a seguinte: quem impõe essa forma, como, e com que objectivo?

O prefixo português "in" exprime as ideias de inclusão, de interioridade ou de movimento para dentro, o que é extremamente relevante se quisermos analisar a partilha e a gestão da informação no contexto das equipas de trabalho multidisciplinar, e perceber como é que esse facto pode gerar diferenças e interferir no agir profissional.

Se a palavra informação indica a imposição de uma forma que é interior e vem de dentro da própria pessoa que é informada ou que se informa, os limites, no âmbito dos quais a informação forma, estão dependentes do contexto hermenêutico que a cada momento cada um de nós é (op. cit:175). Como refere Boff (1997:9), "ler significa reler e compreender, interpretar. Cada um lê com os olhos que tem. E interpreta a partir de onde os pés pisam. Todo o ponto de vista é a vista de um ponto. Para entender como alguém lê, é necessário saber como são os seus olhos e qual é a sua visão de mundo".

Para compreender melhor os limites e as potencialidades da partilha de informação, no âmbito das equipas multidisciplinares, é ainda necessário analisar com mais detalhe a palavra dados, uma vez que, como já foi referido, ela aparece frequentemente associada com a noção de informação. Ora vejamos: o que distingue dados da palavra informação e que relação se estabelece entre elas?

Os significados mais usuais da palavra dados são os seguintes: cada um dos elementos conhecidos de um problema, a base para a formação de um juízo ou cálculo, um indício, uma informação, informações ou representações que podem ser aceites, armazenadas, tratadas ou fornecidas pelo computador ${ }^{6}$. Enquanto adjectivo, a palavra dado significa algo que é permitido, gratuito, afável, propenso a, ou imediatamente presente à consciência antes de qualquer tratamento ${ }^{7}$. Algo dado, é assim algo que é ou que foi dado, no sentido de ter sido objecto da acção de dar. Os dados têm assim um carácter de disponibilidade, de uma presença prévia de gratuitidade. O nosso quotidiano é repleto de dados, alguns dos quais nem reparamos ou valorizamos. Veja-se a quantidade de instrumentos e de informação tecnológica existentes nas sociedades modernas

\footnotetext{
4 (idem).

5 Defendeu como critério de verdade o probabilismo do consenso universal, isto é, aquela posição que acha possível ao homem chegar a algum conhecimento das coisas, sem no entanto atingir a verdade absoluta. A verdade estaria naquilo que pode ser aceite por todos.

${ }^{6}$ www.priberam.pt.

7 (Idem).
} 
que exprimem esse carácter gratuito e imediato de dados factuais. Mais uma vez, apraz realçar nesta análise que, tanto a interpretação dos dados como da informação dependem de uma formação interna de cada um de nós.

Assim, se a questão da informação, como temos vindo a analisar, está relacionada, principalmente, com a forma como cada ser humano concebe o mundo que o rodeia, diferentes profissionais, com diferentes formações e socializações, podem ter diversas concepções de partilha de informação no âmbito da acção profissional.

\subsection{Confidencialidade}

A preservação da informação pode ser abordada tanto pela questão da privacidade quanto pela da confidencialidade. A privacidade é a limitação do acesso às informações de uma dada pessoa, ao acesso à própria pessoa, à sua intimidade, e é a garantia à preservação do seu anonimato e do seu resguardo. A confidencialidade é a propriedade de que a informação não estará disponível ou divulgada a indivíduos, entidades ou processos, sem autorização.

Actualmente, a confidencialidade é considerada como sendo o dever de resguardar todas as informações que dizem respeito a uma pessoa, isto é, à sua privacidade. A confidencialidade é o dever que inclui a preservação das informações privadas e íntimas ${ }^{8}$, e um direito de quem transmite dados pessoais.

No entanto, como já foi referido, no quotidiano profissional podem surgir situações em que é necessário partilhar ou revelar dados pessoais, isto é, a necessidade da quebra da confidencialidade. A quebra de confidencialidade é, neste sentido, a acção de revelar ou deixar revelar informações fornecidas pessoalmente e em confiança.

$\mathrm{Na}$ generalidade dos códigos de deontologia profissional, a quebra de confidencialidade é eticamente admitida quando um benefício real resulte desta quebra, e for o último recurso, após terem sido utilizadas outras possibilidades. Normalmente, este princípio deontológico aparece designado com a expressão "segredo profissional" ou "sigilo profissional". O segredo é uma das manifestações da fidelidade interpessoal nas relações humanas e por isso também o é nas relações profissionais. A palavra segredo provém do latim secretum ( secreto), que significa o que se quer ocultar ou que não se deve dizer; o que não está divulgado. Associado ao segredo encontramos a palavra sigilo, que provém do latim sigillum (marca pequena, sinalzinho, selo), e é, neste sentido, empregue com o mesmo sentido de segredo. Porém, em rigor, traduz o dever de não se revelar o segredo que se sabe ou de que se tem notícia.

Retomaremos este assunto no âmbito das questões ético-legais.

${ }^{8}$ Kennedy Institute of Ethics (1995), Bioethics Thesaurus, 9, KIE - Washington. 


\subsection{Equipas Multidisciplinares}

Uma equipa é um grupo de pessoas que geralmente se une para alcançar um objectivo comum. Ao trabalharem juntas deveriam considerar-se colectivamente responsáveis por ele. No entanto, multidisciplinar significa apenas a justaposição de disciplinas diversas, às vezes sem relação aparente entre elas (Berger, 1972 cit. in Pombo, 1994) ${ }^{9}$. A multidisciplinaridade também ocorre quando a solução de um problema requer a obtenção de informações de uma ou mais ciências ou sectores do conhecimento, sem que as disciplinas que são convocadas por aqueles que as utilizam, sejam alteradas ou enriquecidas por isso (Piaget, 1972, $o p$. cit. $)^{10}$. Sendo assim, multidisciplinar significa um conjunto de disciplinas justapostas sem nenhuma cooperação entre elas (Jantsch, 1972. op. cit.) $)^{11}$. Mas, a multidisciplinaridade orienta-se para a interdisciplinaridade quando as relações de interdependência entre as disciplinas emergem. Passa-se então do simples «intercâmbio de ideias» a uma cooperação e a uma certa compenetração das disciplinas (Palmade, 1979, idem) ${ }^{12}$.

Actualmente, podemos observar a utilização indevida que alguns meios de comunicação fazem do conceito de interdisciplinaridade quando pretendem discutir um problema ou uma determinada situação, como por exemplo: eleições, moda, futebol, violência, etc. . A este propósito, Pombo (2004), refere que "a ideia é sempre a mesma: juntar várias pessoas, de diferentes áreas do conhecimento, e pô-las em conjunto a falar à volta de uma mesa, lado a lado, frente a frente, em círculo ou semicírculo, em presença ou por videoconferência, etc. Cada pessoa fala na sua vez ou procura-se que conversem umas com as outras. Porém, a maior parte das vezes, o que acontece é desentenderem-se, caírem em mal entendidos, conflitos, falhas terríveis de comunicação. Não importa! O que está subjacente a esta mera inventividade de cenários é sempre a ideia embrionária - e muito ingénua - de que a simples presença física (ou virtual) de várias pessoas (como incarnações de vários saberes) em torno de uma

9 BERGER, Guy (1972), “Conditions d'une problématique de l'interdisciplinarité", In Ceri (eds.) L'interdisciplinarité, Problèmes d'enseignement et de recherche dans les Universités, pp. 21-24.,UNESCO/OCDE - Paris.

10 PIAGET, Jean (1972), "Epistemologie des rélations interdisciplinaires", In Ceri (eds.) L'interdisciplinarité, Problèmes d'enseignement et de recherche dans les Universités, pp. 131144, UNESCO/OCDE - Paris.

11 JANSTCH, Erich, (1972), Vers l'interdisplinarité et la transdisciplinarité dans l'enseignement et l'innovation. In Ceri (eds.) L'interdisciplinarité, Problèmes d'enseignement et de recherche dans les Universités, pp. 98-125, UNESCO/OCDE - Paris.

${ }^{12}$ PALMADE, Guy, (1979), Interdisciplinaridad e ideologias, Narcea - Madrid. 
mesma mesa (sobretudo se for "redonda"), criaria automaticamente um real confronto de perspectivas, uma discussão mais rica porque, dir-se-á, mais interdisciplinar"(Pombo, 2004:11). Estas situações nada têm a ver com a interdisciplinaridade, mas sim com disciplinaridade, uma vez que, cada um dos interlocutores debita o seu saber, seguindo apenas os seus princípios e perspectivas teóricas.

Nos nossos dias, as equipas multidisciplinares com funcionamento qualificado compreendem os seus objectivos e estão empenhadas em alcançá-los, de forma compartilhada, por isso, e em primeira instância, a comunicação entre todos deve ser clara e a orientação é, necessariamente, interdisciplinar. Assim, nesta análise, torna-se fundamental clarificar melhor $\mathrm{o}$ conceito de interdisciplinaridade a incluir na dinâmica e funcionamento das equipas de trabalho hodiernas.

\subsection{Interdisciplinaridade}

A interdisciplinaridade, começa por se apresentar como uma mera palavra significante e ambígua, cujo significado é complexo de definir. De acordo com Pombo (1994:10), ninguém sabe exactamente o que é a interdisciplinaridade, o que identifica as práticas ditas interdisciplinares, qual a fronteira exacta a partir da qual uma determinada experiência profissional pode ser dita interdisciplinar e não multidisciplinar, pluridisciplinar ou transdisciplinar.

Mas, ainda assim, a interdisciplinaridade, concordando com a literatura em geral, remete-se para um trabalho em comum, onde se considera a interacção das disciplinas científicas, dos seus conceitos, directrizes, metodologias e procedimentos. Este campo de interacção é, provavelmente, aquele que ninguém consegue definir, pressupondo que o desiderato epistemológico e social de cada profissão é determinado pela sua representação social.

Sabe-se, desde já, que a fragmentação dos conhecimentos ocorrida no contexto da revolução industrial, devido à necessidade de especialização da mãode-obra, está longe de responder à complexidade da realidade social contemporânea. Já no final do séc. XX, emergiram mudanças nos métodos de ensino, com reflexos na acção profissional, que procuravam viabilizar práticas interdisciplinares para que o conhecimento fosse global e integrado.

Se partirmos da premissa, como refere On (2005:156), que nenhuma profissão é absoluta, assim como não o é nenhum conhecimento, sob certo prisma, a interdisciplinaridade pode revelar-se uma alternativa para transpor as fronteiras instituídas entre as profissões, superar as endogenias, deixar de falar só com os mesmos, e, quem sabe, atenuar as vaidades pessoais que o exercício académico, por vezes, ainda insiste em despontar.

A perspectiva de um trabalho interdisciplinar não põe em causa a especificidade das profissões e muito menos os seus campos de especialidade, ela 
aponta para a diversidade e a originalidade dos conhecimentos, permitindo a pluralidade de contribuições e compreensões mais consistentes da realidade social. Parafraseando Etges (1993:79 cit in On 2005:157), "a interdisciplinaridade é o princípio da máxima exploração das potencialidades de cada ciência, da compreensão e exploração dos seus limites, mas, acima de tudo, é o princípio da diversidade e da criatividade". Assim, a interdisciplinaridade evoca o princípio constituinte da diferença e da criação o que, na prática profissional, se reflecte numa postura profissional de conjunto, crítica, propositiva e ética.

Neste argumento, as diversas disciplinas continuam como válidas perspectivas de abordagem dos diferentes aspectos do real. O que de facto está em causa na postura interdisciplinar é o pressuposto epistemológico, de acordo com o qual a verdade completa não ocorre numa ciência isolada, mas num processo de concorrência solidária de várias disciplinas (Severino, 2000:20).

Deste modo, podemos decorrer, como refere Boaventura Sousa Santos, que "não há ignorância em geral, nem conhecimento em geral. Toda a ignorância é ignorância de um certo conhecimento, e todo o conhecimento é a superação de uma ignorância particular" (Santos, 2005:23). Este princípio de incompletude de todos os saberes é a condição da possibilidade de diálogo e de debate entre os diferentes conhecimentos. A sua proposta de uma ecologia dos saberes assenta numa alternativa à monocultura dos saberes científicos que, não pondo em causa a ausência de critérios de hierarquia dos valores entre os diversos saberes, cria um novo tipo de relacionamento entre o saber científico e outras formas de conhecimento. Esta possibilidade não implica conceder igual validade a todos os tipos de saber, mas antes permitir uma discussão pragmática de critérios de validade alternativos, que não desqualifique, à partida, tudo o que não se ajusta ao cânone epistemológico da ciência moderna (idem).

\section{Questões ético-legais}

A Lei n. ${ }^{\circ}$ 67/98 de 26 de Outubro refere-se à protecção de dados pessoais e transpõe para a ordem jurídica portuguesa a directiva 95/46/CE, do Parlamento Europeu e do Conselho, de 24 de Outubro de 1995, relativa à protecção das pessoas singulares no que diz respeito ao tratamento dos dados pessoais e à livre circulação desses dados ${ }^{13}$. O artigo $2 .^{\circ}$ menciona que "o tratamento de dados

\footnotetext{
${ }^{13}$ Esta lei é controlada e fiscalizada pela Comissão Nacional de Protecção de Dados que é uma entidade administrativa independente com poderes de autoridade, que funciona junto da Assembleia da República. Tem como atribuição genérica controlar e fiscalizar o processamento de dados pessoais, em rigoroso respeito pelos direitos do homem e pelas liberdades e garantias consagradas na Constituição e na lei. A Comissão é a Autoridade Nacional de Controlo de Dados Pessoais.
} 
pessoais deve processar-se de forma transparente e no estrito respeito pela reserva da vida privada, bem como pelos direitos, liberdades e garantias fundamentais". Nesta lei, pode observar-se um conjunto de directivas que defendem o direito dos cidadãos à privacidade e confidencialidade no tratamento e protecção dos dados pessoais. Esta prerrogativa é consonante com o artigo XII da Declaração Universal dos Direitos Humanos que refere que "Ninguém será sujeito a interferências na sua vida privada, na sua família, no seu lar ou na sua correspondência, nem a ataques à sua honra e reputação" ${ }^{14}$.

Mais recentemente, a Carta dos Direitos Fundamentais da União Europeia também se pronuncia sobre esta matéria no artigo $8^{\circ}$ onde refere que "Todas as pessoas têm direito à protecção dos dados de carácter pessoal que lhes digam respeito" $"$.

Em Portugal, a protecção da informação está consagrada no âmbito dos direitos dos cidadãos e não apenas como um dever do profissional. Pode observar-se esta protecção na Constituição da República Portuguesa ${ }^{16}$, na Convenção sobre os Direitos do Homem ${ }^{17}$, Códigos Civil, Código Penal e Código Penal Processual, bem como nos diversos Códigos de Deontologia Profissional, quando se prenunciam sobre aspectos relacionados com o sigilo profissional. Desta forma, também a defesa do sigilo profissional passa a ser tanto um direito como um dever, ficando obrigados a respeitar o sigilo profissional, todo o pessoal com acesso directo ou indirecto, a informação de carácter confidencial, devido à sua profissão/função. ${ }^{18}$

Neste âmbito, a actual tutela do segredo profissional, em Portugal, pressupõe, por um lado, a existência de um segredo e, por outro, que a revelação seja feita por quem o devia guardar. Os profissionais abrangidos pelo segredo podem, nesta medida, ser qualificados como "confidentes necessários", que significa todos aqueles cuja profissão ou função suscite e exija a confiança de terceiros.

Podemos ainda espelhar sobre a dupla concepção subjacente à tutela penal. Uma, que privilegia valores pessoais, tendencialmente identificados com a privacidade; outra, que visa valores relacionados com a funcionalidade de

\footnotetext{
${ }^{14}$ Organização das Nações Unidas. Declaração Universal dos Direitos Humanos (1948).

15 Jornal oficial das comunidades europeias, 18/12/2000

${ }^{16}$ Lei Constitucional n. ${ }^{\circ} 1,12$ de Agosto de 2005: "1.Todos os cidadãos têm o direito de acesso aos dados informatizados que lhes digam respeito, podendo exigir a sua rectificação e actualização, e o direito de conhecer a finalidade a que se destinam, nos termos previstos na lei; 2.A lei define o conceito de dados pessoais, bem como as condições aplicáveis ao seu tratamento automatizado, conexão, transmissão e utilização, e garante a sua protecção, designadamente através de entidade administrativa independente".

${ }^{17}$ Entrou em vigor em 3 de Setembro de 1953 e foi ratificado em Portugal pela Lei n. ${ }^{\circ}$ 65/78 de 13 de Outubro.

${ }^{18}$ Consultar Constituição da República Portuguesa - Artigo 26 ${ }^{\circ}$; Código Civil Artigo 80; Código penal - Artigos - 192 e $195^{\circ}$; Convenção sobre os direitos do Homem - Artigo $12^{\circ}$; Convenção sobre os Direitos do Homem e da Biomedicina - Artigo - $10^{\circ}$.
} 
determinadas profissões. Este facto levou a Assembleia Parlamentar do Conselho da Europa a aprovar e recomendar ao Comité de Ministros (Recomendação 1012 (1985) que preparasse uma Recomendação destinada aos Estados-Membros, fixando normas mínimas de protecção do segredo profissional que contemplassem dois princípios. O primeiro, assente na prerrogativa de que "qualquer pessoa que por força do seu estatuto ou das suas funções, da sua profissão ou das suas competências, tenha conhecimento de uma informação sobre a qual a parte interessada deseje, expressa ou implicitamente, que seja guardado segredo, fica adstrita à obrigação de segredo profissional". O segundo, que "as excepções a esta obrigação devem ser previstas por lei ou ordenadas por um tribunal regular e respeitar o artigo $8^{\circ}$, n. $^{\circ}$ 2, da Convenção de Salvaguarda dos Direitos do Homem e das Liberdades Fundamentais"19.

Existem, no entanto, aspectos do segredo profissional que merecem ser tratados autonomamente e que podem motivar dificuldades de grau diferente em relação às equipas multidisciplinares. Segundo Mireille (1982:44), uma prestigiada penalista francesa, a questão do segredo profissional desenvolve-se segundo três momentos denominados, por esta autora, de palavra confiada, silêncio imposto e palavra reencontrada. Os dois primeiros momentos referemse à informação recolhida e à obrigação de segredo. Já a análise do terceiro momento - palavra reencontrada - pode revelar-se mais complexa. A expressão palavra reencontrada, refere-se a situações em que o profissional a quem foi confiado o segredo pode ou deve falar. A dispensa da obrigação de sigilo decorre de uma razão imperativa à luz do direito, ou porque uma autoridade, nomeadamente a administração da justiça, impôs a quebra do segredo.

Como já foi referido, o sigilo profissional é oponível a quem se encontra numa relação geralmente apelidada de confidente-necessário. Trata-se, por regra, de pessoas (advogados, médicos, psicólogos, assistentes sociais, etc.) que estabelecem ou mantêm com o portador do segredo relações profissionais que o obrigam a revelar aspectos da sua privacidade ou intimidade. Normalmente, estes profissionais têm que obter qualificações próprias, agrupam-se em ordens ou associações e estão sujeitos a Códigos Deontológicos.

\footnotetext{
${ }^{19}$ Artigo $8^{\circ}$ "1- Qualquer pessoa tem direito ao respeito da sua vida privada e familiar, do seu domicílio e da sua correspondência; 2- Não pode haver ingerência da autoridade pública no exercício deste direito senão quando esta ingerência estiver prevista na lei e constituir uma providência que, numa sociedade democrática, seja necessária para a segurança nacional, para a segurança pública, para o bem estar económico do país, a defesa da ordem e a prevenção das infracções penais, a protecção da saúde ou da moral, ou a protecção dos direitos e das liberdades de terceiros."Secretaria do Tribunal Europeu dos Direitos do Homem, Setembro de 2003.
} 
Efectivamente, o portador do segredo, pode ou não ter uma margem de escolha (em muitos casos, não) quando estabelece ou mantém uma relação profissional. No seio de instituições em que os profissionais fazem parte dos quadros e estão sujeitos a regras rígidas de provimento, a relação de confiança poderá ser confrontada com as normas éticas institucionais e profissionais em simultâneo. As profissões têm um limiar ético ou deontológico, mas a garantia da preservação das informações, além de uma obrigação legal contida no Código Penal, no Código Civil e na maioria dos Códigos de Deontologia Profissional, é um dever prima facie $^{20}$ de todos os profissionais e também das instituições.

Por tudo isto, o princípio do sigilo profissional não é apenas um princípio normativo mas, sobretudo, é um princípio ético, que resulta de um clima de confiança recíproca entre o profissional e aquele a quem presta o serviço e entre os diversos profissionais envolvidos nessa prestação.

\section{Considerações sobre "novos caminhos" para as equipas multidisciplinares}

Considerando que as equipas multidisciplinares devem incluir a possibilidade de um trabalho interdisciplinar, as palavras-chave das novas abordagens ao trabalho em equipa multidisciplinar são a delegação de poder (empowerment), a participação e o desenvolvimento. Wisinski (1994:88), relaciona os seguintes elementos na dinâmica de uma equipa, que interage e procura os objectivos comuns:

1. PARTICIPAÇÃO: deve haver uma participação equilibrada, não havendo dominante, nem ausente; deve haver equilíbrio;

2. TRANSACÇÃO DE IDEIAS: a responsabilidade de cada membro da equipa é preparar as suas ideias antecipadamente e apresentá-las à equipa de forma lógica e equilibrada, possibilitando efectiva contribuição;

3. RENÚNCIA: este é o elemento mais importante no relacionamento da equipa. Quando os membros conseguem renunciar uma posição profissional em prol do grupo, todos saem a ganhar;

\footnotetext{
${ }^{20}$ Este conceito foi proposto por Sir David Ross, em 1930. Ele propunha que não há, nem pode haver, regras sem excepção. O dever prima facie é uma obrigação que se deve cumprir, a menos que ela entre em conflito, numa situação particular, com um outro dever de igual ou maior porte. Um dever prima facie é obrigatório, salvo quando for sobrepujado por outras obrigações morais simultâneas. Ross WD. (1930), The right and the good, Oxford, Clarendon, 19-36.
} 
4. AVALIAÇÃO: saber avaliar os resultados alcançados pela equipa no final de um período (de um trabalho ou de um projecto), procurando eliminar os pontos menos positivos e encontrar, em conjunto, melhores alternativas;

5. RELACIONAMENTO: todos são responsáveis pelo relacionamento quando são membros de uma equipa. Se houver um conflito pessoal, deve ser resolvido pelas partes o mais rápido possível, pois um conflito no grupo prejudica o todo e, muitas vezes, impede a realização proveitosa dos objectivos a alcançar;

6. REALIZAÇÃO DAS FUNÇÕES: é de extrema importância que todos estejam conscientes da sua responsabilidade em relação à realização das funções que competem ao grupo. Num relacionamento interdependente, a falha de um dos membros pode ter repercussões em toda a equipa.

Estes elementos, no entanto, precisam de ser relacionados com outros aspectos e perspectivas para que possam ter efectividade. Uma abordagem crítica, mais alargada, deverá incluir os seguintes ângulos de análise:

- O contexto social (económico, político e cultural) onde se forma e se exerce a profissão;

- As mudanças na organização e prática das equipas multidisciplinares;

- O domínio do técnico e a subalternização do domínio ético;

- Repensar os princípios e valores profissionais;

- Equacionar a determinação de um projecto de ética profissional interdisciplinar assente em alianças e partilhas.

Este último ângulo de análise pressupõe o compromisso dos seus intervenientes com a competência e exige aprimoramento intelectual contínuo. A sua efectiva concretização pressupõe três propósitos de base:

1- A Enunciação das referências teóricas que fundamentem as concepções de ética no que diz respeito aos valores, aos princípios e modos de ser éticomorais dos diversos profissionais no seu conjunto - Debate teórico;

2- A decomposição das práticas, que envolve o comportamento de cada categoria profissional de acordo com as suas acções, orientadas pelas suas visões de mundo, juízos de valor, responsabilidades, compromisso social e a possibilidade de associação ao conjunto das acções dos outros profissionais Análise de situações concretas;

3 - Uma orientação normativa, expressa num código de deontologia profissional, onde se norteie o comportamento dos profissionais, sem que 
cada profissão perca a sua identidade e campo de actuação, e onde seja explicitada a direç̧ão social, como uma exigência estatutária referenciada aos objectivos da instituição - Comissão de Ética.

A determinação de um código de deontologia profissional, cuja independência de cada profissão deverá preservar, no sentido de não serem postos em causa os princípios e valores fundamentais que as configuram, deverá envolver todos os profissionais e abordar, no âmbito da partilha de informação e confidencialidade, os seguintes aspectos:

- Independência (ter a consciência de que se é o único responsável pelas próprias decisões e assumir esta responsabilidade);

- Integridade e objectividade (não se deve, em circunstância alguma, retirar vantagens de qualquer natureza do exercício das suas funções, o que implica honestidade e sinceridade);

- Princípios de tratamento da informação;

- Confidencialidade da informação do utente;

- Acções que acreditem os profissionais (em relação aos usuários, à instituição e à sociedade).

O sucesso que possa resultar de um projecto desta natureza depende, acima de tudo, do envolvimento de todos os intervenientes num processo vivificador de discussão de correlações e reciprocidades que, no seu limite, encontre mais pontos comuns do que divergências.

\section{Conclusão}

Neste artigo, procurou-se indicar alguns dos contornos fundamentais para um melhor entendimento do processo de partilha de informação e confidencialidade no âmbito das equipas multidisciplinares, a partir de uma reflexão ética das questões conceptuais, legais e práticas que lhe estão conexas.

O impacto que poderá emergir desta análise, é a possibilidade de a transformar numa área de debate, aliança e projecto, frente aos desafios hodiernos que se colocam às profissões e que põem em prática a defesa e garantia dos Direitos Humanos.

A informação, com toda a sua riqueza e relevância na identificação de possibilidades, de oportunidades e de ameaças, não depende de quaisquer dados ou conjunto de dados enquanto tais e por si só, por mais vastos e detalhados que o sejam, mas dos objectivos e da formação daqueles que a utilizam, partilham e confidenciam.

Os novos desafios das equipas multidisciplinares passam, necessariamente, pela compreensão cognitiva da interdisciplinaridade enquanto sensibilidade à 
complexidade, capacidade de permuta e reconhecimento dos limites e potencialidades de cada profissão, e também por uma mudança de atitude.

A dimensão ética das profissões está ligada, precisamente, a essa abertura à sensibilidade e à atenção, à interrogação pelo valor e sentido do que fazemos e sobre a forma em que nos relacionamos com o que fazemos.

A determinação de um projecto profissional multidisciplinar poderá constituir-se como uma estratégia de alianças interprofissionais, mas também como uma forma de tornar confiáveis os resultados da equipa em relação aos usuários, à instituição e à sociedade em geral.

A ética profissional está arrolada com as visões de mundo, incorporadas socialmente pela educação moral primária e por outras instâncias educativas, que os profissionais possuem. Por isso, tão importante como ter referências éticas é saber reconhecer os seus limites e poder avaliar em cada contexto e em cada situação as zonas de cruzamento, interdependência ou choque com outras éticas. 


\section{BIBLIOGRAFIA}

ANDER-EGG E. e FOLLARI R. (1993), Trabajo Social e Interdisciplinaridad, $2^{a}$ ed., Editorial Humanitas - Buenos Aires.

BANKS, S. (2001), "Ética em Fragmentos", MOURO, H. e SIMÕES (org.), 100 Anos de Serviço Social, 101-124, Quarteto, - Coimbra.

(1997), "Códigos profesionales de ética", in Ética y Valores en el Trabajo Social, 81-108, Paidós - Barcelona.

BARROCO, M. L. (2001), "Os Fundamentos Sócio-históricos da Ética”, in Serviço Social, Ética, Deontologia \& Projectos Profissionais, 31-47, CPIHTS, VERAS, ICSA - Lisboa, Madrid, São Paulo.

BOFF L. (1997), A Águia e a Galinha: uma metáfora da condição humana, Multinova - Lisboa.

CARIA, T. H (org.) (2005), Saber Profissional: análise social das profissões em trabalho técnico-intelectulal,. Almedina - Coimbra.

CUSHWAY B. e LODGE D. (1993), Organização Planeamento $e$ Comportamento: estruturas, cargos e funções, comunicação, motivação, Clássica Editora - Lisboa.

DIAS, M. O. (2004), "Reflexões sobre a ética no quotidiano da profissão", in Gestão e Desenvolvimento, $\mathrm{n}^{\circ} 14$, Universidade Católica Portuguesa - Centro Regional das Beiras.

FIAS - Federação Internacional de Serviço Social e AIESS - Associação Internacional de Escolas de Serviço Social (2004), Ética no Serviço Social: Declaração de Princípios - Adelaide, Austrália.

GOLIN, A. E Ducanis, A. (1981), The interdisciplinary team: a handbook for the education of exceptional children, Rockville, MD: Aspen.

GONÇALVES, J. L. R. (1999), "Ética: segredo profissional”, in rev. CEJ, V. 3, $\mathrm{n}^{\circ} 7$ - Brasília.

GONÇAlVES, M. L. M. (2007), Código Penal Português, $18^{\mathrm{a}}$ ed., Almedina Coimbra.

ILHARCO, F. (2003), Filosofia da Informação: uma introdução à informação como fundação da acção da comunicação e da decisão, Universidade Católica Editora - Lisboa.

LOPES, M. do C. (2005), Tecnologias de Informação e Comunicação: incidência do seu uso no desenvolvimento local, Palimage Editores - Viseu.

MIREILLE D-M. (1982), A propos du secret professionnel, Recueil Dalloz Sirey, $38^{\mathrm{e}}$ cahier - Paris.

MOSCOVICI. F. (1995), Equipes dão certo: a multiplicação do talento humano, ed. José Olympio - Rio de Janeiro.

MUNHOZ, D. E.N. (1996), "Trabalho Interdisciplinar: realidade e utopia", in Serviço Social \& Sociedade, nº 51, Ano XVII, 167-171- São Paulo. 
NETTO, J. P., (2001), “ A Construção do Projecto Ético-político do Serviço Social frente à crise Contemporânea", in HENRÍQUEZ, B. Alfredo (org.), Serviço Social, Ética, Deontologia \& Projectos Profissionais, Cpihts, Atlântida, Veras, ICSA, 11-29 - Lisboa, Madrid, São Paulo.

ON, M. L. R. (1995), "O Serviço Social e a perspectiva interdisciplinar", MARTINELLI, M. Lúcia e al (org.), O Uno e o Múltiplo nas Relações entre as Áreas do Saber, Cortez, 152-169 - São Paulo.

POMBO, O. et al. (1994), A Interdisciplinaridade: Reflexões e Experiências, $2^{\mathrm{a}}$ ed., Texto - Lisboa.

POMBO, O. (2004), Interdisciplinaridade: ambições e limites, Relógio d'Água Lisboa.

PORTUGAL Gabinete de Documentação e Direito Comparado da ProcuradoriaGeral da República, (1997), PARECERES - os segredos e sua tutela. v. VI. Gabinete de Documentação e Direito Comparado da Procuradoria-Geral da República, (sobre "segredo médico", p. 301-364) - Lisboa.

PORTUGAL Gabinete de Documentação e Direito Comparado da ProcuradoriaGeral da República, (1998), PARECERES - vida privada - utilização da informática. v. VII. Gabinete de Documentação e Direito Comparado da Procuradoria-Geral da República - Lisboa.

RIOS, T., A. (2001), Ética e Competência, 11 a ed., Cortez - São Paulo.

SÁ, J. L. M. (org.) (2000), Serviço Social e Interdisciplinaridade: dos fundamentos filosóficos à prática interdisciplinar no ensino, pesquisa e extensão, $3^{\mathrm{a}}$ ed., Cortez - São Paulo.

SANTOS, B. S. (2005), O Fórum Social Mundial: manual de uso, Edições Afrontamento - Porto.

SAVATER, F. (2005), Ética para um Jovem, Dom Quixote - Lisboa.

SCHERMERHORN Jr. et al. (2005), Fundamentos do Comportamento Organizacional, $2^{\mathrm{a}}$ ed., Bookman - Porto Alegre.

SEVERINO A. J. (2000), "Subsídios para uma reflexão sobre novos caminhos da interdisciplinaridade", in SÁ, Jeanete L. M. (org.), Serviço Social e Interdisciplinaridade: dos fundamentos filosóficos à prática interdisciplinar no ensino, pesquisa e extensão, $3^{\mathrm{a}}$ ed., Cortez, 11-21 - São Paulo.

WISINSKI, J. (1994), Como Resolver Conflitos no Trabalho, Campus - Rio de Janeiro.

ZARAGOZÁ J. V. et al (2000), Servicios Sociales e Interdisciplinaridad, Seting - Valência.

\section{Internet:}

verbojuridico.pt, 2011-06-24

www.ufrgs.br, 2010-07-25

www.priberam.pt, 2010-07-30 